\title{
ESTRATÉGIAS PARA IMPLANTAÇÃO DE MELHORIA DO CONTROLE GLICÊMICO NO INTRAOPERATÓRIO EM PACIENTES DE ALTO RISCO
}

Leopoldo Muniz da Silva, Arthur de Campos Vieira Abib, Saullo Queiroz Silveira, Wilson Porfírio de Medeiros Nunes.

Introdução: Alterações glicêmicas estão associadas ao aumento da morbimortalidade cirúrgica. $O$ adequado controle glicêmico permanece um desafio no intraoperatório (IO).

Objetivo: Avaliar o impacto de um programa de educação médica continuada em relação a adesão ao protocolo de controle glicêmico no IO.

Métodos: Foram avaliados, por meio de auditoria mensal de prontuários, as medidas de adesão a um protocolo de controle glicêmico para pacientes de alto risco (diabéticos, cirurgias de grande porte e neonatos). Campanhas de divulgação ao time cirúrgico foram realizadas ao longo do ano de 2017 e em 2018, foi implantado um programa gerenciado de educação médica continuada, no qual o anestesiologista não conforme recebia orientação direcionada, artigos científicos atuais para leitura e após, era submetido a um teste de múltipla escolha para evidência de efetividade de treinamento. O impacto do projeto de melhoria implantada foi avaliada quanto à durabilidade, tendência e efetividade.

Resultados: A média de adesão ao protocolo em 2017 foi de 54\% (desvio padrão = 4,45\%), com valores mínimos de 20\% e máximos de 64\% na adesão. Após estratégia inicial, não foi observada melhoria duradoura e tendência positiva na adesão ao protocolo. Em janeiro de 2018 , foi implantado um programa de educação médica continuada gerenciado (PEMCG). Nas avaliações subsequentes da adesão ao protocolo, observou-se uma tendência positiva de crescimento na adesão. A média da adesão, após a implantação do programa, foi de $80,8 \%$ (desvio padrão de $7,45 \%$ ), com diferença estatisticamente significativa em relação ao período pré-implantação $(<0,001)$.

\begin{tabular}{|c|}
\hline $\begin{array}{c}2017 \\
\text { Estratégia }\end{array}$ \\
\hline $\begin{array}{c}2018 \\
\text { Estratégia }\end{array}$
\end{tabular}

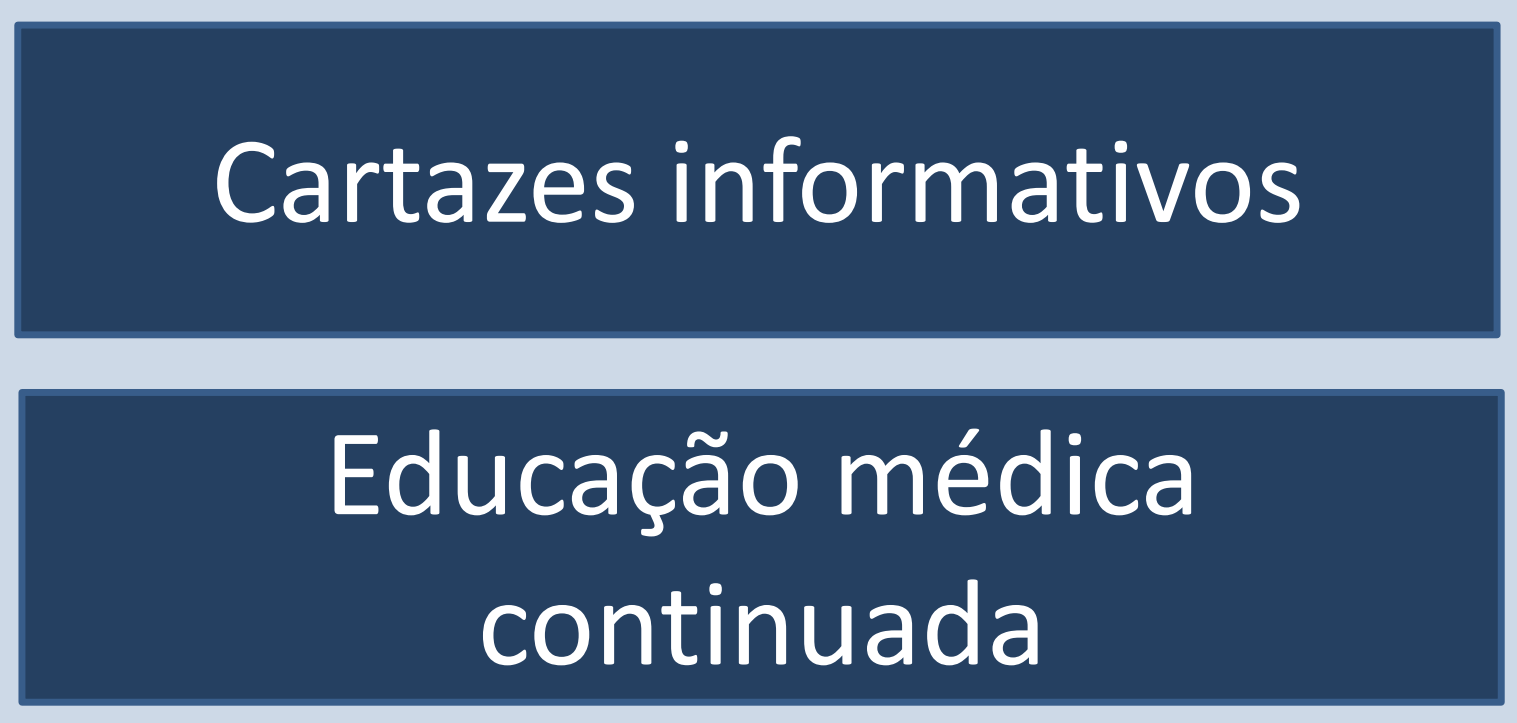

\begin{tabular}{|c|}
\hline $\begin{array}{c}\text { Lembretes em } \\
\text { salas }\end{array}$ \\
\hline $\begin{array}{c}\text { Treinamento } \\
\text { focado }\end{array}$ \\
\hline
\end{tabular}

Aula expositiva

Pós-teste (efetividade)

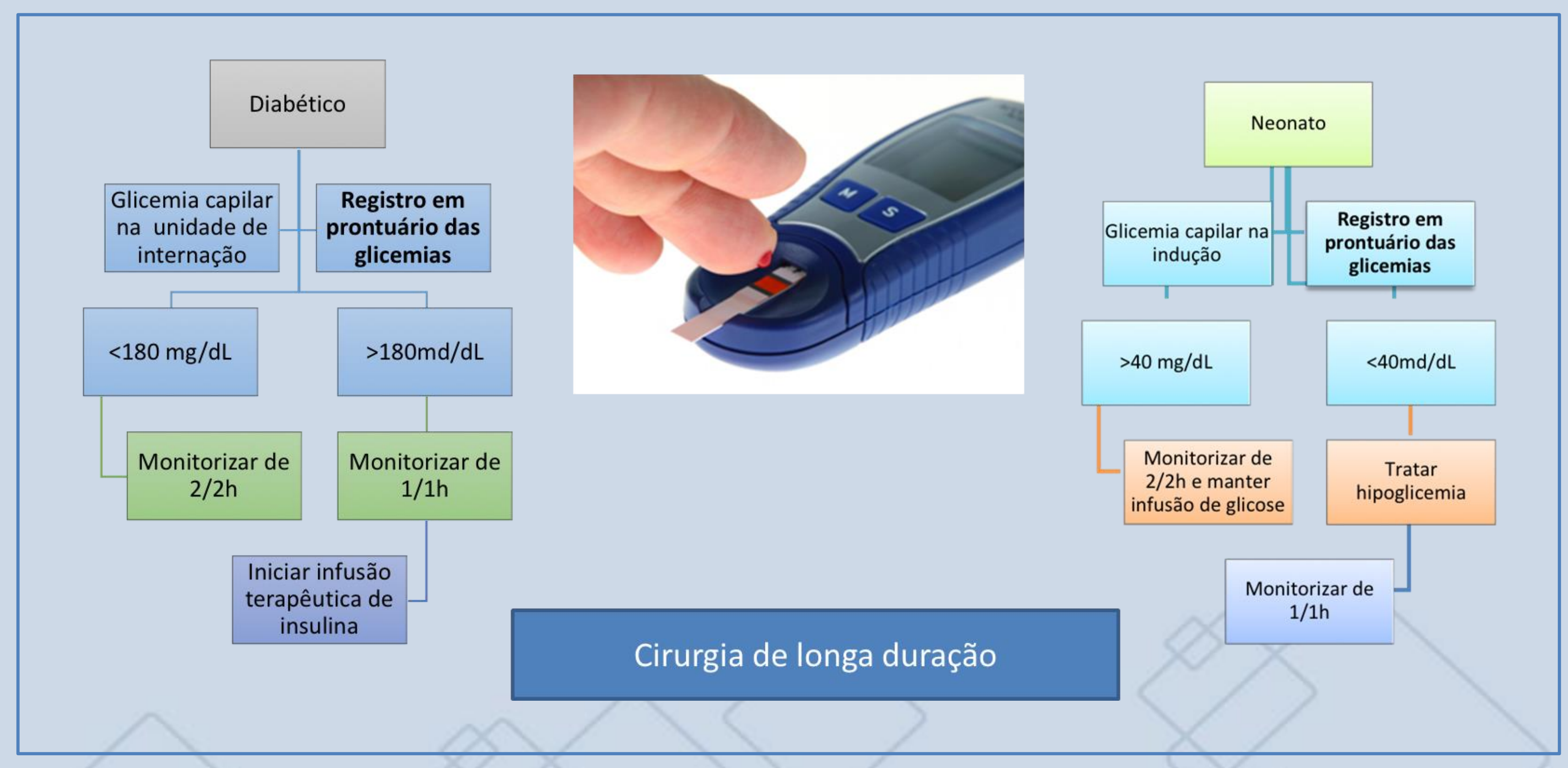

Figura 1. Algoritmo assistencial do protocolo

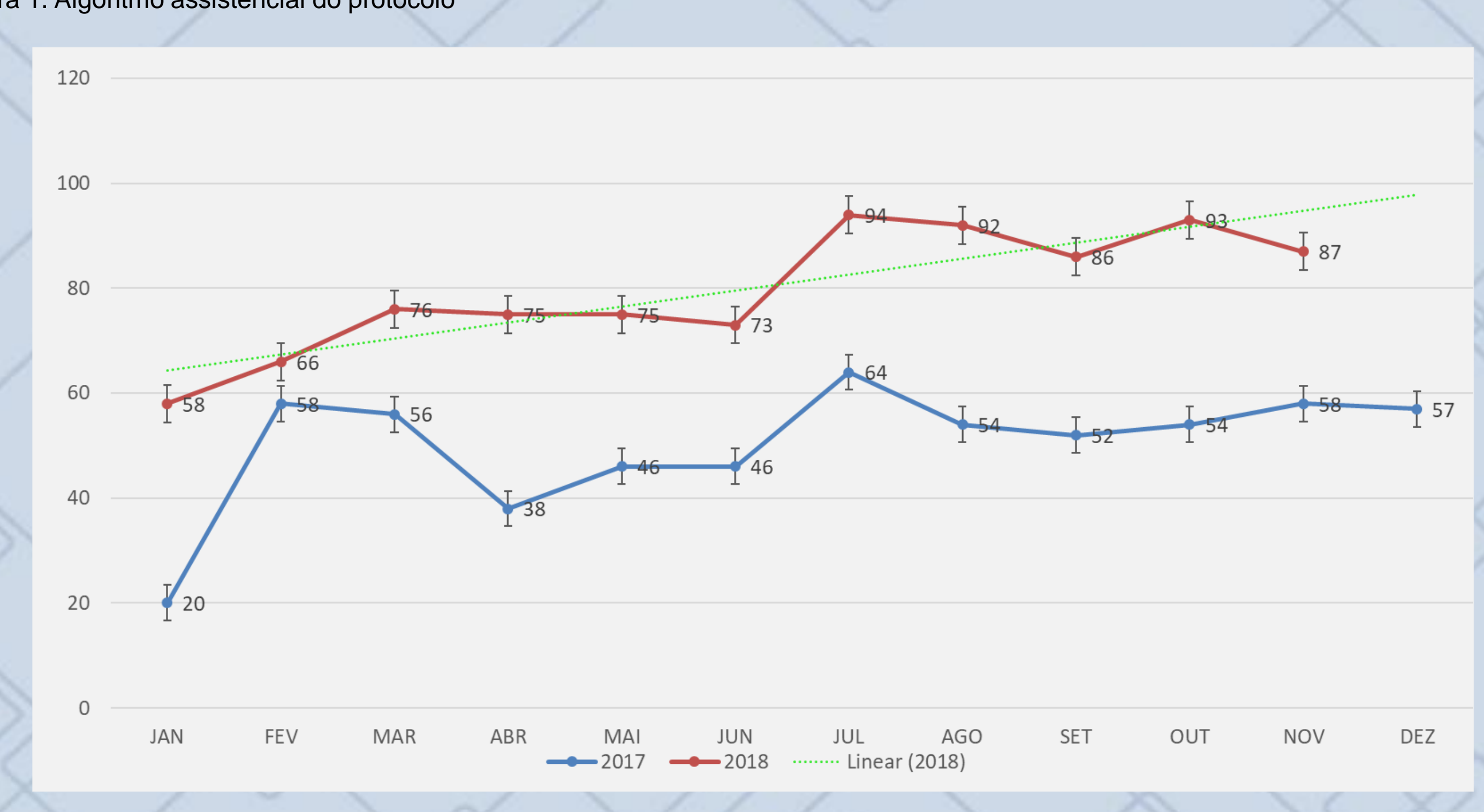

Figura 2. Conformidade em relação à adesão e adequação do protocolo de controle glicêmico no 10 (2017-1018). Valores expressos

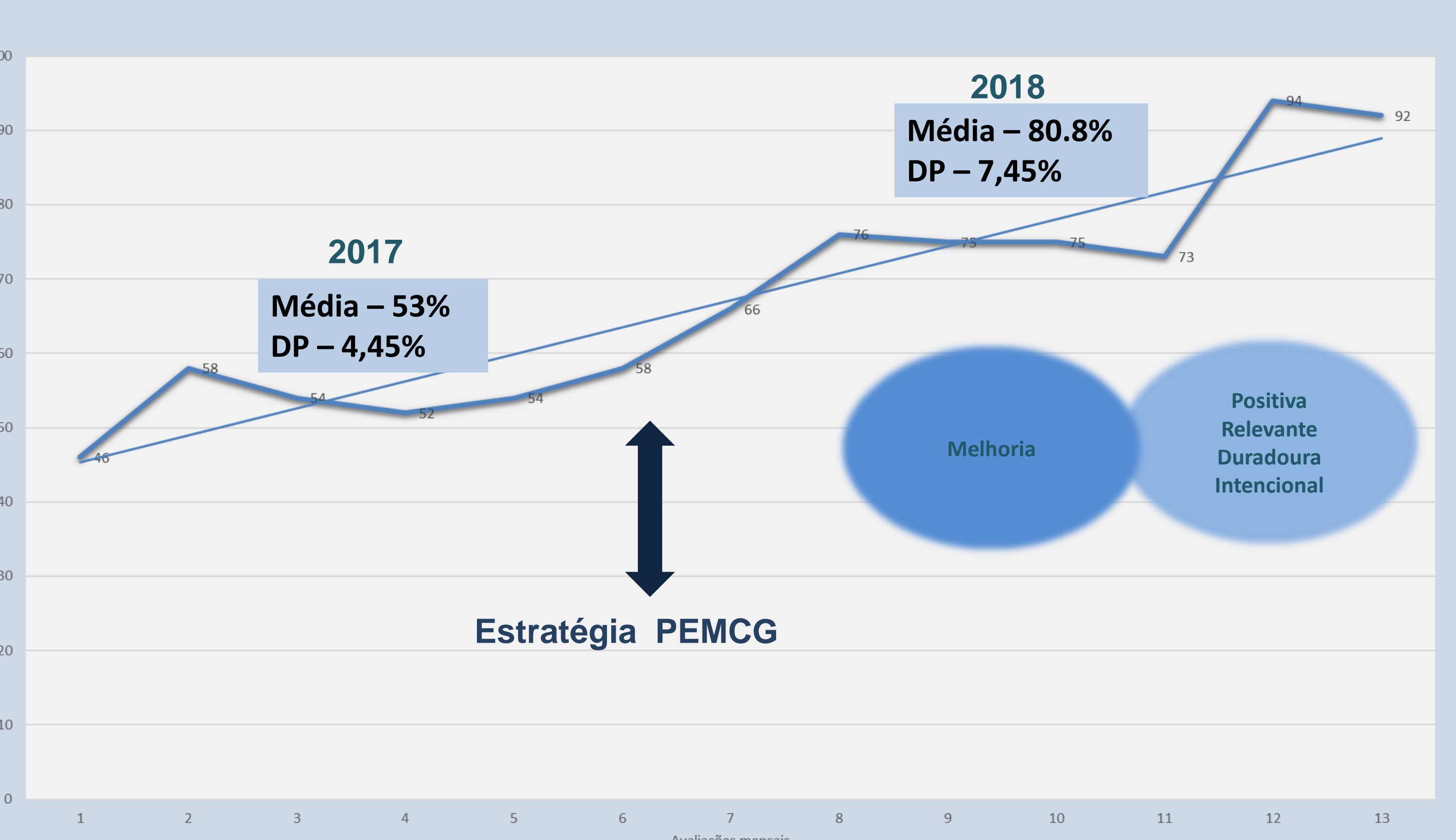

Figura 3. Comparativo entre estratégias adotadas em relação à conformidade e adesão ao protocolo de controle glicêmico no 10 (20171018). Valores expressos em \%. $\mathrm{N}=332$ pacientes. Teste $t: p<0,05$. Houve diferença entre a média de conformidade entre os dois perídos analisados (antes e após implantação do programa de educação médica continuada - PEMCG). Foram comparadas as taxas de adesão antes ( 7 avaliaçōes) e após a ação planejada e intencional ( 7 avaliaçōes após) para avaliação de melhoria.
Conclusão: A educação médica continuada, com demonstração da importância do controle glicêmico no 10 por meio de evidências científicas atuais e treinamento focado e direcionado, com avaliação de efetividade por meio de teste, proporcionou uma melhoria positiva, duradoura e efetiva para um melhor controle glicêmico em pacientes de alto risco. 